European Journal of Logistics, Purchasing and Supply Chain Management

Vol.8 No.3, pp.17-38, August 2020

Published by ECRTD UK

ISSN 2054-0930 (Print), ISSN 2054-0949 (Online)

\title{
THE EFFECT OF INTEGRATED PHARMACEUTICAL LOGISTIC SYSTEM ON USER SATISFACTION AND LOGISTICS PERFORMANCE OF HIV/AIDS COMMODITIES: EVIDENCE FORM PUBLIC HOSPITALS IN ETHIOPIA
}

\author{
Mengistu Bogale Ayele (PhD) \\ Addis Ababa University, School of Commerce, Department of Accounting and Finance \\ mengistubogale@gmail.com, Tel: +251911619760
}

Tibeb Zeleke (MLSCM)

City Government of Addis Ababa, Health Bureau

tzeleke198@gmail.com, Tel: +251911857487

\begin{abstract}
This study was conducted to assess the effect of IPLS on user satisfaction and logistics performance of HIV/AIDS commodities. Data were collected from 127 respondents in six public Hospitals using questionnaire and interview. The study employed explanatory design with mixed research method. The data collected and analyzed indicated that IPLS enhances their satisfaction which increases job performance of users. IPLS resulted in big improvement in the accuracy of logistics by improving planning, decision making, productivity and overall logistics objectives. The regression analysis indicated that all the independent variables have strong and positive effect on user satisfaction and thereby on Logistics performance except system quality which did not have strong and positive effect on user satisfaction due to factors specific to the Ethiopian environment as indicted in the interview such as turnover of trained staff, lack of trainings and other factors. Future research may be conducted by incorporating other variables that affect IPLS, covering wider geographic area, and also incorporating private hospitals.
\end{abstract}

KEY WORDS: system quality, information quality, service quality, user satisfaction, cultural factors, HIV/AIDS commodities

\section{INTRODUCTION}

Health is one of the crucial elements for the development of any country. To achieve goals set in the Millennium Development Goals, the Government of Ethiopia has developed various programs and strategies. However, the evaluation of the Health Sector Development Program (HSDP) I and II indicated that the pharmaceuticals supply management system of Ethiopia has been suffering of several problems including non-availability, un-affordability, poor storage and stock management and irrational use of pharmaceuticals. Various products used to be managed using vertical systems (Berhane, 2017). HIV/AIDs pharmaceuticals and supplies were distributed by the PFSA distribution networks though PFSA central, PFSA branches and then 
ISSN 2054-0930 (Print), ISSN 2054-0949 (Online)

to health facilities using monthly LMIS reports. These all lead to lots of distribution networks, warehouses, human resources for managing the products. As a result there were high wastage of products and it demanded high resources for managing products at all levels and created gaps in mobilization of resources from different stakeholders.

To solve these problems in public health facilities, the FMOH initiated a comprehensive supply chain strategic planning process emphasizing the integration of all products into one supply chain (PFSA, 2014). In late 2006, the Ministry approved the Pharmaceutical Logistics Master Plan (PLMP) through which, Pharmaceuticals Fund and Supply Agency (PFSA) was established in 2007 by Proclamation No. 553/2007. To execute this mandate, PFSA, in collaboration with different partners who were currently working in the health sector developed and began implementing the Integrated Pharmaceuticals Logistics System (IPLS) in 2009.

IPLS is the term applied to the single pharmaceuticals reporting and distribution system based on the overall mandate and scope of the PFSA. It aims are to ensure that patients always get pharmaceuticals they need. IPLS integrates the management of essential pharmaceuticals including pharmaceuticals that were used to be managed vertically: HIV/AIDS, Malaria, TB and Leprosy, EPI, MCH and purchased essential drugs. It is the primary mechanism through which all public health facilities obtain essential and vital pharmaceuticals (FMOH, 2010). IPLS integrates the supply chain management of all types of pharmaceuticals (medicines, medical supplies and equipment, and laboratory chemicals and reagents) in the public health sector. It has three main components including the policies and guidelines for logistic management information system (LMIS), inventory control and storage of pharmaceuticals at all levels of the supply chain system throughout the country.

Integrated pharmaceutical logistics system (IPLS) is the system which can ensure access to quality, safe, affordable and uninterrupted supply of vital and essential Medicines, if it is operated perfectly at different level of supply chain members (Nigussie, 2017). Hence, Ethiopia has a number of health programs that require efficient pharmaceuticals supply chain system for their effective and efficient implementation (Berhane, 2017).

Consequent investment in vertical program systems improved availability for those program specific commodities (effectiveness) but all this lead to lots of distribution networks, warehouses, human resources for managing the products. As a result there were high wastage of products, and it demanded high resources for managing products at all levels and created gaps in mobilization of resources from different stakeholders (Berhane, 2017). In addition, prior studies tried to assess only the system implementation process, challenges and opportunities without indicating what factors influence the performance of IPLS. No prior studies were conducted to observe the factors that explain IPLS performance. This study has also introduced the culture of the organization and its effect on the performance of IPLS on top of other factors identified to influence an information system's performance. Lastly, many studies in the past used only either quantitative or qualitative research approaches but in this research the mixed research approach was adopted to take advantage of both approaches. 
ISSN 2054-0930 (Print), ISSN 2054-0949 (Online)

With the introduction of IPLS, PFSA worked to establish an integrated health commodity supply chain that would include all health program commodities, and would connect all levels (from health facility-PFSA branches-PFSA central/RHB/FMOH) with accurate and timely data for decision making (PFSA, 2014). IPLS is expected to facilitate the logistics performance of HIV/AIDS commodities. Well-designed and practical IPLS is essential for the supply management cycle of HIV/AIDS commodities is to function effectively and efficiently (Tadesse, 2015). Hence this paper will addresses the performance status of IPLS in public Hospitals found in Addis Ababa and issue and challenges faced during the performance.

Managing health commodity through the Integrated Pharmaceutical Logistics System (IPLS) is a strategy to enhance the smooth flow of commodities and prevent frequent stock outs of critical items that could hinder continuous provision of quality health services. Its effective performance is crucial for the government to produce the intended outcome in health care provision. Hence follow up of its performance as well as filling the gaps identified during performance is the concern of stakeholders including FMOH. The result of the study will be useful for administrators of HIV/AIDS commodities in public hospital in Addis Ababa health bureau and different stakeholders involved in the performance of IPLS. It will also have academic contribution by adding empirical evidence to the existing body of knowledge on IPLS for public Hospitals. Furthermore, it will also give an insight to any individual who has an interest to further research on pharmaceutical logistic system.

The study focused on assessing the effect of IPLS on the logistics performance of HIV/ AIDS commodities in public Hospitals. To make the research work more manageable, the research was delimited to HIV/AIDS commodities only. This is because such medicines are so critical that can't be interrupted and there is large number of patients treated in the hospital. In addition, the study was conducted in selected public Hospitals in Addis Ababa as the hospitals are managed in homogeneous manner under the supervision of the same bureau or minster organization (MOH, 2010). This study did have some limitations. Firstly, the respondents were busy to complete questionnaires. Close follow up effort was put to maximize collection of questionnaires and minimize this limitation. Another limitation may be respondent bias. Triangulation of different data collection methods (questionnaire and interview) was used again to minimize this part of the limitation.

\section{REVIEW OF RELATED LITERATURE}

In this part the theoretical aspects of IPLS performance and logistics performance of HIV/AIDS commodities will be presented. It begins with the basics of logistics management, identifies attributes of IPLS performance and effect on user satisfaction as well as logistics performance of HIV/AIDS commodities.

Berhanemeskel et al. (2016) stated that supply chain management of essential health commodities, including high-value medicines like Antiretroviral (ARV) medicines, involves a series of activities to guarantee the continuous flow of products from the manufacture to consumers. The nature of ART and the specific characteristics of ARV medicines and how they 
ISSN 2054-0930 (Print), ISSN 2054-0949 (Online)

are used pose particular challenges for managing the supply chain for ARV medicines. Effective pharmaceutical supply management and inventory control avoid stock out, loss due to unnecessary expiry, theft and ensure that the desired pharmaceutical products are available at all times in adequate quantity. But in many low and middle income countries (LMICs), the capacity of the pharmaceutical supply management system has always been challenging and weak. The ARV supply chain management has become increasingly difficult due to increasing number of people on ART, increasing number of sites providing ART and a greater diversity of different ARV regimen (Berhanemeskel et al., 2016). Moreover, there are certain common challenges associated with the quantification of ARV medicines and supplies mainly in LMICs. Data on ART services and ARV medicine supply are limited and when available, are often unreliable or insufficient to be used for quantifying ARV medicine requirements. An accurate quantification based on reliable data is essential for all health commodities but more so for HIV/AIDS related commodities because uninterrupted access for patients must be ensured. Shortage of critical medicines and supplies in health facilities may compromise appropriate clinical management (Tilahun, 2014).

Mudzteba (2014) stated pharmaceutical logistics data are collected, processed, and reported through LMIS, increasing the likelihood of an adequate supply of EDs. An effective LMIS may be manual or computerized collecting essential data about stock status and consumption. It ensures accountability, a reduction in supply imbalances (stock outs and overstocks), and efficient, cost-effective pharmaceutical logistics. Because a pharmaceutical logistics system cannot function effectively without timely, accurate LMIS data, the LMIS is an essential tool. It provides personnel responsible for pharmaceutical logistics with the information they need to react or, more important the information they need to anticipate demand (Mudzteba, 2014). To be effective, LIMS should be equipped with adequate trained staff, forms, equipments, and facilities. However, some studies showed that there is a problem in this regard.

Information system effectiveness is the extent to which a specific information system actually contributes to achieving organizational goals, that is, its effect on organizational performance (Hamilton and Chervany, 1981). The influence IPLS effectiveness is factored under information system factors and supply chain management factors.

According to Sirsat and Sirsat (2016), the information system produces information that is, afterwards, communicated to the recipient who is subsequently influenced by the information. On level of information transfer Sirsat and Sirsat (2016) cited the work of DeLone and McLean concluded that there are six distinct categories or aspects of information systems: (a) system quality, (b) information quality, (c) Service quality, (d) Usage, (e) user satisfaction, and (f) Net benefit. 


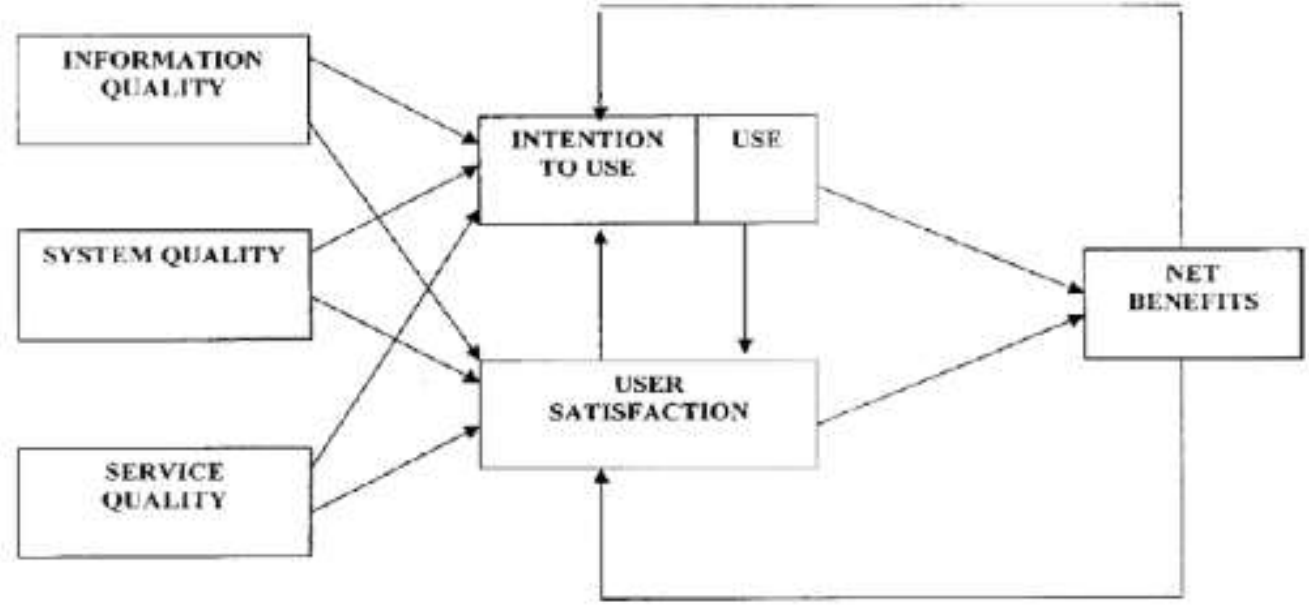

Figure 1. The DeLone and McLean Model of System Success (from Sirsat and Sirsat, 2016)

Prior studies on IPLS emphasized on system implementation predominantly. Those that relate with organizational performance assess only one case study or limited case Hospitals. Most of the studies were descriptive by their nature of design. In this study, explanatory factors that influence IPLS performance and its effect on logistics performance of HIV/AIDS commodities in 6 hospitals was assessed. The study is believed to bridge the gap in previous studies. In addition, culture is believed to influence user satisfaction and system implementation which is a new construct obtained from other studies. Below is the research model to be used in this study (adapted from Sirsat and Sirsat 2016).

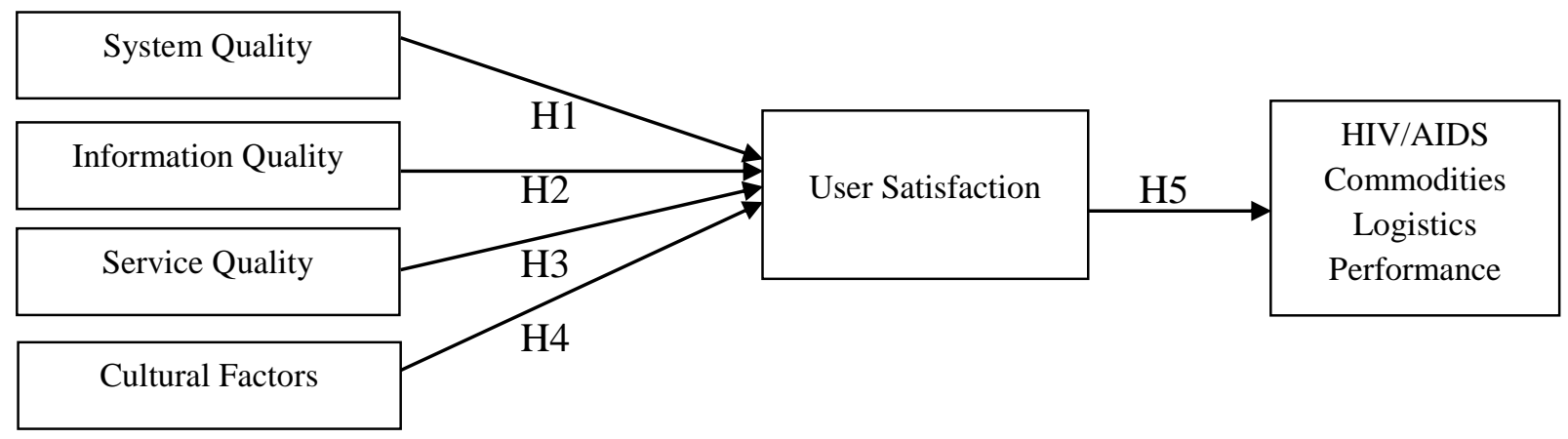

Figure 2. The Conceptual Framework (Based on Sirsat and Sirsat, 2016)

The conceptual framework illustrates how the independent variables (components of IPLS performance) and the mediating variable (user satisfaction on IPLS) influence logistics performance of HIV/AIDS (the dependent variable). Intention to use in the original model was assumed to be reflected in user satisfaction in our model. IPLS factors are information quality, 
European Journal of Logistics, Purchasing and Supply Chain Management

Vol.8 No.3, pp.17-38, August 2020

Published by ECRTD UK

ISSN 2054-0930 (Print), ISSN 2054-0949 (Online)

system quality, cultural factors which influence user satisfaction and HIV/AIDS logistics performance.

\section{System quality}

According to Halawi et al. (2007), Dreheeb, Basir and Fabil (2016) and Sirsat and Sirsat (2016) the term quality reflects excellence, value, conformity to specification, and quality meeting customer expectation. The value of information system can be realized by improving profit margins for the organization, providing easy-to-use and useful applications, and designing easily maintainable system. Thus system quality is an important aspect in IS success. Measures of the system quality which have been used in the literature are flexibility, stability, reliability, usefulness, user-friendly interface, ease of use and response time. Access and retrieval of information when needed, to meet work demands and to return requests quickly have been noted to be inherent to system quality. Hence, according to Halawi et al. (2007), Dreheeb, Basir and Fabil (2016) and Sirsat and Sirsat (2016) system quality positively correlates with user satisfaction and better benefit realization. Hence, same applies to IPLS and it can be hypothesized as follows:

\section{H1: IPLS Quality significantly and positively influences user satisfaction}

\section{Information quality}

Halawi et al. (2007), Sirsat and Sirsat (2016) and many others in Information systems research argued that information system quality concept is related to system output that is useful for business users. The most important informational insufficiency the managers suffer from is plenty of irrelevant information. Information quality problems, such as incorrect information due to program or data errors and irrelevant information arise due to changed user requirements. Some important dimensions studied under Information quality like relevance, understandability, accuracy, conciseness, completeness, up to date, timeliness, and usability. Sirsat and Sirsat (2016) further stressed that information quality refers to the ability to acquire information that is sufficient, that meets end-user needs, and is comprehensive in nature. Many researchers in different studies have measured information quality and the most common measures were of timeliness, completeness, ease of understanding, relevance, security, consistency, accuracy and personalization, importance, usefulness, readability etc. Sirsat and Sirsat (2016) found in their empirical study that measuring system characteristics like the content of database, aggregation of details, human factors, response time, and system accuracy positively correlates to user satisfaction and system performance. Hence, it can be hypothesized as follows:

\section{H2: IPLS information Quality significantly and positively influences user satisfaction}

\section{Service Quality}

The dimension service quality represents the quality of the support that the users receive from the IS department and IT support personnel. Organizational success is delivered by the service 
Vol.8 No.3, pp.17-38, August 2020

Published by ECRTD UK

ISSN 2054-0930 (Print), ISSN 2054-0949 (Online)

provider. On time and error free performance by IS unit improves organizational efficiency (Halawi et al. 2007; Sirsat and Sirsat, 2016). Some of the dimensions are measured by most of the researchers in their work like Assurance, Empathy Flexibility, Interpersonal quality, intrinsic quality, IS training, Reliability, Responsiveness. IS services will become better aligned with organizational goals, resulting in improved quality of decision making and improved profitability, better expectancy of customer demands and more accurate sales forecasting (Halawi et al., 2007; Sirsat and Sirsat, 2016). Hence, it can be hypothesized as follows:

\section{H3: IPLS Service quality significantly and positively influences user satisfaction}

\section{Cultural Factors}

In many systems literature, cultural factors are believed to influence the level of diffusion and utilization of the system. According to Al-Jumeily and Hussain (2014) cultural neutrality has been identified as a blind spot in previous Technology Acceptance models (TAMs), because culture has been demonstrated in the literature to exert a major influence on acceptance. Unfortunately, the literature shows that technology is predominantly developed for the young and some studies are concerned with the investigation of how technology acceptance cuts across national borders. Often the practice is to take the existing knowledge regarding technology acceptance in developed western nations and to relate it to other cultures based on cultural beliefs and values (Hofstede, 1980).

Al-Jumeily and Hussain (2014) identified three primary continuums drawn from the cultural dimensions theory of Hofstede that are used to identify the differences in the cultural factorsindividualism/collectivism, uncertainty avoidance, and power distance.

Individualism/Collectivism is the degree to which individuals are integrated within any group. In individualism the emphasis is on individual roles and rights, where individuals are expected to stand up for themselves, their own family and their own affiliations. In contrast, in collectivism, individuals behave as members of an organization or group, so that their family is that group or organization to which they pay unquestioning loyalty. Uncertainty

Avoidance is defined as the tolerance of a society for uncertainty. It measures the extent of coping with anxiety by avoiding uncertainty. High uncertainty-avoidance cultures implement rules and laws to support plans that are followed step-by-step to minimize unknown and ambiguous circumstances. On the other hand, low uncertainty-avoidance cultures have as few rules as possible, they tolerate changes and accept a changeable environment and situations; these cultures tend to be pragmatic cultures.

Power Distance reflects the way people accept and perceive power differences. High powerdistance cultures accept autocratic power relationships, where people are not equal to each other, and their positions are classified hierarchically from superior to subordinates (Akour et al., 2006). In contrast, low power-distance cultures experience more democratic relationships, 
European Journal of Logistics, Purchasing and Supply Chain Management

Vol.8 No.3, pp.17-38, August 2020

Published by ECRTD UK

ISSN 2054-0930 (Print), ISSN 2054-0949 (Online)

and equality is practiced by all members of the society, who have the right to criticize and change the decision making of those who are in power (Teo et al. 2008).

As Ziefle and Jakobs (2010) as well as Romi (2011) affirm, people use technology within a cultural and social context, and these influence how humans behave towards technology. Often a whole host of factors differ across cultures, and these factors include social taboos, political and legal constraints, together with religious, ethical and traditional values. Therefore, technology users across the globe have different perceptions, styles of thinking, cognitive and cultural values, and assumptions. Hence, it can be claimed that the above argument applies to IPLS as one category of system and it can be hypothesized as follows:

\section{H4: Good Culture of using IPLS significantly and positively influences user satisfaction}

\section{User Satisfaction}

Halawi et al. (2007), Dreheeb, Basir and Fabil (2016) as well as Sirsat and Sirsat (2016) stated that user satisfaction is defined as the recipient's response to the use of the output of an information system. They mentioned studies which found that user satisfaction closely related with user attitude; therefore, studies which include user satisfaction as a success measure should ideally also include measures of user attitudes. Sirsat and Sirsat (2016) further asserted that user satisfaction can be measured indirectly through information quality, system quality, and other variables. Hence it is used as a mediating variable between system performance and organizational performance (Halawi et al. 2007; Dreheeb, Basir and Fabil 2016). Hence, it can be hypothesized as follows:

\section{H5: User satisfaction of IPLS significantly and positively influences Logistics performance of HIV/AIDS commodities.}

\section{Organizational Impact}

According to Sirsat and Sirsat (2016), organizational impact represents the firm-level benefits received by an organization because of Information System applications. Measure of organizational performance which might be appropriate for measuring the contribution of IPLS is return on investment. Several authors have developed constructs to measure IPLS impacts on organizations. Effective Management Information System contributed to meeting organizational goals. The success of information systems impacts not only on firm performance but also on industry structure. Operating cost reduction, staff reduction, productivity gain, increased revenues, sales, market share, profits and increased work volume. Sirsat and Sirsat (2016) stated that effective use of information system contributes to the success of individuals, groups or organizational profits. They concluded in their study about E-Commerce that net benefits is the most important construct since it captures the balance of positive and negative impacts of the e-commerce on customers, suppliers, employees, organizations, markets, 
industries, economies, and even societies. This same logic applies for IPLS and net benefit of IPLS is performance of HIV/AIDS commodities.

The ILS (integrated logistic system) was designed to address shortcomings in the previous vertical systems. By clarifying roles, simplifying forms, streamlining processes, and consolidating responsibility for key logistics functions at MSD, Tanzania hopes to improve product availability and customer service. Stock out rates were relatively low in both integrated and nonintegrated regions, The data collected for the study suggest that the integrated system itself did not necessarily cause higher stock out levels for certain products. Instead, it appears that some issues with system design (inventory control and buffer stocks), delays and stock availability issues at the central level, and some instability during the beginning of the transition to an integrated system may have translated into stock outs (USAID PROJECT, 2011).

Integrated supply chains have collateral benefits for a health system. A cohesive, wellperforming public health supply chain helps build the foundation for a strong pharmaceutical management system, provides essential information for managing health programs and financing mechanisms, and helps to achieve the level of accountability exemplified in the commercial sector. Integration has helped companies learn to deliver good quality products efficiently, on time, and securely to their customers. These improvements have translated into increased profits, more viable companies, and better customer service. Integrated supply chain links all the actors involved in managing essential health commodities into one cohesive supply chain management organization. Integration helps client's access quality healthcare services and supplies (Berhane, 2017).

\section{RESEARCH METHODOLOGY}

The type of research design used was an explanatory research whereby the influence that IPLS will have on the logistics performance of the HIV/AIDS commodities in the selected hospitals. Explanatory studies will help manipulate the independent variable to influence the mediating and dependent variables. A mixed research method of both quantitative and qualitative ones was used to conduct this study. This mix of methods helped to triangulate the responses from different sources to better improve the conclusion from the study. Quantitative data were gathered via survey from questionnaire on Likert Scale. Qualitative data were from interview of pharmacy heads about IPLS in the Hospitals selected for the survey above.

There are 14 government owned hospitals in Addis Ababa, Ethiopia, of which four are under the Federal Ministry of Health, one is university hospital, six are general hospitals under Addis Ababa City Administration Health Bureau and the other three are army and police hospitals. The study was conducted on six of these government hospitals selected on convenient bases and considering the mix of the Hospitals, three hospitals under Addis Ababa City Administration Health Bureau and the other three hospitals are under the Federal Ministry of Health to get proper mix of hospitals. The three from AACA are Minilik II Referral Hospital, Ras Desta Hospital and Zewuditu Memorial Hospital. The other three are from Federal government which includes St Paul Hospital, Alert Hospital and Black Lion Specialized 
Vol.8 No.3, pp.17-38, August 2020

Published by ECRTD UK

ISSN 2054-0930 (Print), ISSN 2054-0949 (Online)

Hospital. The unit of analysis for this study are pharmacy professional of the Hospitals. From each hospital all the pharmacy section professionals were taken as respondents of this study. Two types of data sources were used to collect the qualitative and quantitative types of data from primary sources of data. Questionnaires were distributed for the target respondents identified above to gather detailed information about the performance the IPLS and the logistics of HIV/AIDS commodities. Likert scale questions were designed to assess the level of performance. The instrument was customized from prior studies. In addition interviewing key informants using structured interview and observations was used to answer why and how question.

Head of the hospitals (the Medical Director) were approached having support from the school of commerce to obtain consent and permission to undertake the data collection process. Then, the questionnaires were distributed and collected in person for the respondents. For the interview, pharmacy heads were approached for convenient time and place of interview. Even if interview guide may be used as the starting point, additional questions may be raised based on the responses for the earlier questions. The quantitative data were entered and analyzed using SPSS for analysis. Descriptive statistics (mean, median and percentage) were computed and summary results were presented using tables and graphs. Correlation coefficient was computed to see the association between IPLS performance with the logistic performance of HIV/AIDS commodities. The qualitative data obtained from interview were summarized using thematic analysis (similarity and differences). Health information is so private and highly sensitive matter. Hence, much degree of confidentiality were maintained during data collection process and no name of the participating subjects (respondents) is revealed on any part of the research paper. Data were collected from 127 respondents who were working in 6 pharmacies of public hospitals in AA. The reliability of the data was checked using Cronbach's Alpha. As indicated in table 4.1 above, all the variables indicated Cronbach's Alpha of 0.751 and above which are in the acceptable range of minimum value of 0.70 as indicated by Tavakol and Dennick (2011). The Validity was also checked by using a survey instrument from prior studies, that was pretested for completeness and use in Ethiopian context. This approach will address both face validity, construct validity and content validity.

\section{RESULT, DISCUSSION AND INTERPRETATION}

The respondents were asked their demographic data to check if they are the right respondents for this research and their profile data are presented as follows: 
European Journal of Logistics, Purchasing and Supply Chain Management

Vol.8 No.3, pp.17-38, August 2020

Published by ECRTD UK

ISSN 2054-0930 (Print), ISSN 2054-0949 (Online)

\begin{tabular}{|c|c|c|c|}
\hline & & \begin{tabular}{|l|} 
Frequency \\
\end{tabular} & Percent \\
\hline \multirow[t]{7}{*}{ Hospitals Visited } & Alert Hospital & 27 & 21.3 \\
\hline & $\begin{array}{l}\text { Black Lion Specialized } \\
\text { Hospital }\end{array}$ & 37 & 29.1 \\
\hline & Gandi Memorial Hospital & 12 & 9.4 \\
\hline & Ras Desta Hospital & 19 & 15.0 \\
\hline & St Paul Hospital & 17 & 13.4 \\
\hline & Zewuditu Memorial Hospital & 15 & 11.8 \\
\hline & Total & 127 & 100.0 \\
\hline \multirow{4}{*}{$\begin{array}{l}\text { Level of } \\
\text { Education }\end{array}$} & Diploma & 18 & 14.2 \\
\hline & BSc Degree & 102 & 80.3 \\
\hline & Masters & 7 & 5.5 \\
\hline & Total & 127 & 100.0 \\
\hline \multirow{5}{*}{$\begin{array}{l}\text { Years of } \\
\text { Experience }\end{array}$} & $1-5$ & 44 & 34.6 \\
\hline & $6-10$ & 48 & 37.8 \\
\hline & $11-15$ & 34 & 26.8 \\
\hline & $>16$ & 1 & .8 \\
\hline & Total & 127 & 100.0 \\
\hline \multirow{5}{*}{$\begin{array}{l}\text { Managerial } \\
\text { position }\end{array}$} & Top Level & 2 & 1.6 \\
\hline & Middle Level & 19 & 15.0 \\
\hline & Lower Level & 27 & 21.3 \\
\hline & No position & 79 & 62.2 \\
\hline & Total & 127 & 100.0 \\
\hline \multirow{3}{*}{$\begin{array}{l}\text { Sex of } \\
\text { Respondents }\end{array}$} & Female & 49 & 38.6 \\
\hline & Male & 78 & 61.4 \\
\hline & Total & 127 & 100 \\
\hline
\end{tabular}

Table1: Demographic profile of respondents

As indicated in the table above, the data for this research were collected from 6 Hospitals (3 Federal Level and 3 from City Government of Addis Ababa). These data are believed to be representative of all government hospitals in the country as they are homogeneous in governance, operating procedures, budget administration and other matters. The sample included small, medium and large Hospitals with pharmacists from 12 to 37 per hospital in number. The qualification of majority of respondents was BSc Degree $(80.3 \%)$ followed by Diploma holders (14.2\%). This indicated that the respondents were able to understand the issues in the questionnaire and provide appropriate responses about IPLS and its impact on logistics performance of HIV/AIDS commodities. As indicated above, the majority of the respondents have 6 to 10 years of experience (37.8\%) followed by those up to 5 years of experience (34.6\%). Of course, quite good number of respondents (26.8\%) also has experience of 11 to 15 years. 
The experience of the respondents, like their academic qualification, is a factor that indicates that the respondents are fit for the research process.

The managerial position of the respondents indicated that the top level managers were very few and large number of respondents were without managerial position $(62.2 \%)$. This implies that the respondents were the actual operators of the system (IPLS). But participation of lower level of mangers $(21.3 \%)$ and middle level mangers $(15 \%)$ will help to get the view of management about the system. As indicated in the table, the gender distribution of the respondents was $61.4 \%$ males and $38.6 \%$ females. Even if the number of females is less than male counter parts, both groups were fairly represented as the number of females is lesser in all aspects of organizational affairs. This also implies that the respondents were properly picked up from both groups. Before data analysis was conducted, the data were tested for multi Co-linearity and normality and found to be fit. A large sample size (more than 30 respondents) is believed to be normally distributed (Ghasemi and Zahedias1 2012). As this study used 127 respondents, the data tend to be normally distributed. In the next part, descriptive analysis of factors influencing IPLS performance data will be presented.

\section{System Quality}

System quality measures conformity to specifications, and meeting customer's expectation (Sirsat and Sirsat, 2016). This is reflected by assessing whether IPLS is friendly to handle, error free, fulfils management requirements and a secured system. The table below summarizes responses from the participants:

\begin{tabular}{|l|r|r|}
\hline Items & \multicolumn{1}{|c|}{ Mean } & \multicolumn{1}{c|}{$\begin{array}{c}\text { Std. } \\
\text { Deviation }\end{array}$} \\
\hline IPLS is friendly to handle & 4.33 & .86 \\
\hline IPLS is error free & 3.62 & 1.28 \\
\hline $\begin{array}{l}\text { IPLS fulfils mgt } \\
\text { requirements }\end{array}$ & 4.04 & .89 \\
\hline IPLS is secured system & 3.84 & 1.07 \\
\hline Overall system quality & 4.10 & .88 \\
\hline
\end{tabular}

Table 2: System Quality(N=127)

The respondents stated the least mean result (3.62) and the highest Standard deviation (1.284) for the question whether the system is error free. The highest mean score system quality component was the system being friendly to handle (4.33) followed by the system fulfilling management requirements (4.04). Considering all the variables together, system quality has overall mean score of 4.10 and standard deviation of 0.88 which is not bad result.

During the interview, participant E commented the following about the system quality:

"The main challenge of system quality is turnover of trained staff. When new staffs are replaced, proper training how to operate IPLS is not given". 
This indicated that the system quality may not have problem but the staff having prerequisite knowledge.

Participant B also added the following two points about the system quality:

"One challenge is no skill upgrading training of the existing employees. Another main problem is lack of proper pharmacy infrastructure".

According to this participant, skill set problem is not only for new employees but for existing ones also. Continuous skill upgrading training is needed for all employees to properly utilize the system.

\section{Information Quality}

Information quality is the outcome of a quality system (Sirsat and Sirsat, 2016). Information quality is measured in terms of whether the information IPLS produced is accurate, precise, easy to find, complete and understandable.

The table below summarizes responses from the participants:

\begin{tabular}{|l|r|r|}
\hline & Mean & \multicolumn{1}{|c|}{$\begin{array}{c}\text { Std. } \\
\text { Deviation }\end{array}$} \\
\hline IPLS Information accurate & 3.8425 & 1.00337 \\
\hline IPLS Information is precise & 4.0866 & .84538 \\
\hline IPLS Information easy to find & 4.1181 & .93956 \\
\hline IPLS provides complete info & 4.1024 & 1.02225 \\
\hline IPLS info is understandable & 4.0236 & .88609 \\
\hline $\begin{array}{l}\text { Overall Info quality(Grand } \\
\text { mean) }\end{array}$ & 4.0236 & .83061 \\
\hline
\end{tabular}

Table 3: information quality $(\mathrm{N}=127)$

The respondents stated the least mean result (3.84) and the highest standard deviation (1.02) for the question whether the information is accurate. The highest mean score information quality component was the Information easy to find (4.11) followed by the information provides complete information (4.10). Considering all the variables together, information quality has overall mean score of 4.02 and standard deviation of 0.83 which is not bad result.

From the interview, participant $\mathrm{C}$ commented the following about the information quality:

"The main challenge of information quality is in IPLS there are different reporting formats like Bin card, stock record card, IFRR and RRF. These report formats are not frequently updated. This is due to budget shortage to prepare the formats".

This indicated that the information quality is compromised no due to the system itself rather availability of accessories.

Participant $\mathrm{F}$ also added the following about the information quality: 
Vol.8 No.3, pp.17-38, August 2020

Published by ECRTD UK

ISSN 2054-0930 (Print), ISSN 2054-0949 (Online)

"The employees complete the forms carelessly due to work load or lack of motivation".

This indicated that motivational packages shall be availed for employees to encourage them perform their duty properly.

\section{Service Quality}

Service quality is success dimension is delivered by the service provider. On time and error free performance by Is unit improves organizational efficiency (Sirsat and Sirsat, 2016).service quality is measured IPLS easy to install, updates available, support provided by authority, flexibility and supplementary variables. The table below summarizes responses from the participants:

\begin{tabular}{|l|l|l|l|}
\hline & N & Mean & $\begin{array}{l}\text { Std. } \\
\text { Deviation }\end{array}$ \\
\hline IPLS easy to install & 127 & 3.9528 & 1.02243 \\
\hline IPLS updates available & 127 & 4.0000 & 1.09109 \\
\hline Support provided by authority & 127 & 4.0945 & .90355 \\
\hline $\begin{array}{l}\text { IPLS flexible to adjust to new } \\
\text { work }\end{array}$ & 127 & 4.0000 & .97590 \\
\hline Supplementary variable & 127 & 3.9449 & .92845 \\
\hline Overall service Quality & 127 & 3.9449 & .87566 \\
\hline
\end{tabular}

Table 4: IPLS Service Quality

The respondents stated the least mean result (3.94) and the highest standard deviation (1.09) for the question whether the service quality is Supplementary variable. The highest mean score service quality is support provided by authority (4.09) followed by the service updates available and flexible to adjust to new work the same mean value result (4.00). Considering all the variables together, service quality has overall mean score of 3.94 and standard deviation of 0.875 which is not bad result.

\section{Cultural Factors}

Cultural factors are believed to influence the level of diffusion and utilization of the system AlJumeily and Hussain (2014) cultural neutrality has been identified as a blind spot in previous Technology Acceptance models (TAMs). Al-Jumeily and Hussain (2014) identified three primary variables drawn from the cultural dimensions theory of Hofstede that are used to identify the differences in the cultural factors individualism, uncertainty avoidance, and power distance. The table below summarizes responses from the participants: 
European Journal of Logistics, Purchasing and Supply Chain Management

Vol.8 No.3, pp.17-38, August 2020

Published by ECRTD UK

ISSN 2054-0930 (Print), ISSN 2054-0949 (Online)

\begin{tabular}{|l|l|l|}
\hline & Mean & $\begin{array}{l}\text { Std. } \\
\text { Deviation }\end{array}$ \\
\hline Individualism affects IPLS use & 3.9921 & 1.07272 \\
\hline $\begin{array}{l}\text { Uncertainty avoidance affects IPLS } \\
\text { use }\end{array}$ & 3.9685 & 1.09788 \\
\hline Power distance influences IPLS use & 3.8976 & 1.00660 \\
\hline Overall cultural factors & 3.9843 & 1.02341 \\
\hline
\end{tabular}

Table 5: Cultural Factors $(\mathrm{N}=127)$

From the table above, the least mean result (3.89) and the highest standard deviation (1.09) is for the question whether power distance influences IPLS use. This indicated there is good communication among the different power hierarchies due to absence of power distance. The highest mean score of cultural factors is if individualism affects IPLS use (3.99) followed by the factor of uncertainty avoidance affects IPLS use (3.96).

All employees work for their assignments individually instead of collaborating among themselves. Considering all the variables together, cultural factors has overall mean score of 3.98 and standard deviation of 1.02. This indicated that the IPLS is not affected mush by cultural factors such as individualism, uncertainty avoidance and power distance. This is a good organization culture and should be encouraged further.

\section{User Satisfaction}

User satisfaction is the recipients to the use of the out of information system. (Sirsat and Sirsat, 2016).user satisfaction is measured IPLS enables accomplish tasks; helps perform quickly, improves job performance, increases productivity and enhances effectiveness. The table below summarizes responses from the participants:

\begin{tabular}{|l|l|l|}
\hline & Mean & Std. Deviation \\
\hline IPLS enables accomplish tasks & 4.11 & .89 \\
\hline IPLS helps perform quickly & 4.1969 & .88227 \\
\hline IPLS improves job performance & 4.2283 & .78870 \\
\hline IPLS increases productivity & 4.2126 & .86950 \\
\hline IPLS enhances effectiveness & 4.0945 & .95480 \\
\hline Overall user satisfaction & 4.1890 & .78409 \\
\hline
\end{tabular}

Table 6: User Satisfaction ( $\mathbf{N = 1 2 7 )}$

The respondents stated the least mean result (4.09) and the highest standard deviation (0.95) for the question whether the user satisfaction is enhances effectiveness. As they indicated low result for system quality, its contribution to their effectiveness is lesser. The highest mean score user satisfaction is improves job performance (4.22) followed by IPLS increases productivity (4.21). Even if the system has some quality problems, it facilitates their job performance. Considering 
Vol.8 No.3, pp.17-38, August 2020

Published by ECRTD UK

ISSN 2054-0930 (Print), ISSN 2054-0949 (Online)

all the variables together, user satisfaction has overall mean score of 4.18 and standard deviation of 0.78 which is good result. This indicated that users are so much satisfied with the system and this shall further be enhanced in the future by proper training, system update and other attributes of IPLS.

\section{Logistics Performance of HIV/AIDS Commodities}

Logistics performance of HIV/AIDS commodities is the final outcome of well designed IPLS and user satisfaction. The respondents were asked about the logistics performance of HIV/AIDS commodities and the responses were summarized as below:

\begin{tabular}{|l|c|r|}
\hline \multicolumn{1}{|c|}{ Items } & Mean & Std. Deviation \\
\hline IPLS enhances planning logistics & 4.1890 & .94055 \\
\hline IPLS enhances logistics decision making & 4.2913 & .84619 \\
\hline IPLS improves accuracy of logistics & 4.3071 & .78186 \\
\hline IPLS increases logistics productivity & 4.2047 & .85763 \\
\hline IPLS enables achieve logistics objectives & 4.0394 & .92926 \\
\hline Overall logistics performance & 4.2441 & .80392 \\
\hline
\end{tabular}

Table 7: Logistics Performance of HIV/aids Commodities ( $\mathrm{N}=127)$

The respondents stated the least mean result (4.03) for the question whether IPLS enables achieve logistics objectives. This is prime objective of the system and a better result was expected. The highest mean score was for the issue whether IPLS improves accuracy of logistics (4.30) followed by IPLS enhances logistics decision making (4.29). Considering all the variables together, user satisfaction has overall mean score of 4.24 and standard deviation of 0.8 which is good result. This indicated that IPLS is facilitated the work of HIV/AIDS logistics performance very much. Modern systems used to increase efficiency and effectiveness and as well reduce cost. This capacity shall be better utilized by improving it in the future based on feedback obtained from users and their level of satisfaction. 


\subsection{Correlation Matrix of Dependent and Independent Variables}

The correlation matrix of the independent, mediating and dependent variables is shown below:

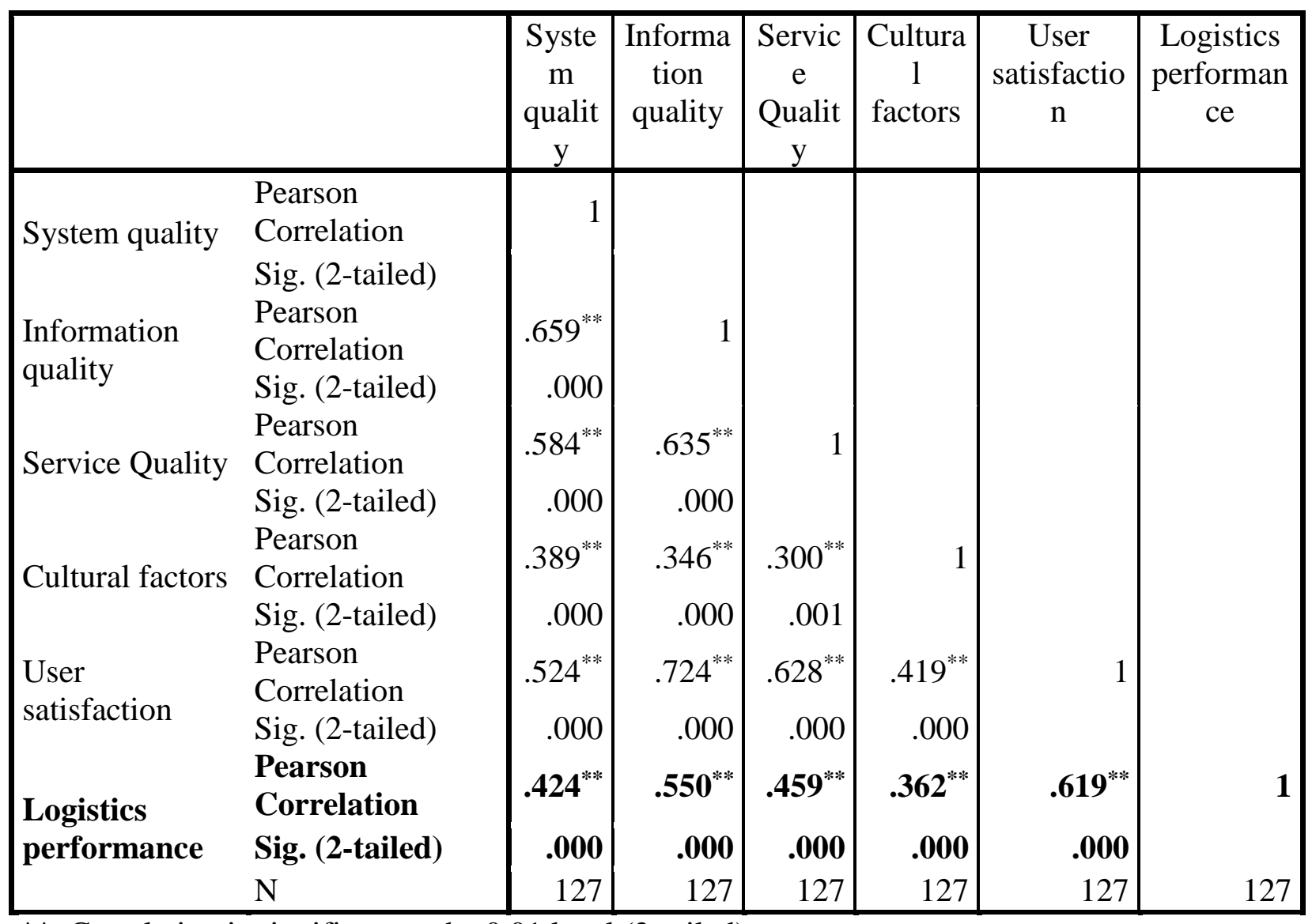

**. Correlation is significant at the 0.01 level (2-tailed).

Table 8: Correlation Matrix of Variables

The table indicated that each construct is highly correlated to the dependent variable indicating that change in each independent variables results in change in the dependent variable. The relationship is strong at one percent level of significance. It is obvious that the components shall be correlated one another and with the dependent variables as system quality should lead to information quality supported by good working culture and resulting in user satisfaction which in turn leads to better logistics performance (Halawi et al., 2007; Dreheeb, Basir and Fabil, 2016 and Sirsat and Sirsat, 2016). There was strong positive relationship between user satisfaction and Logistics Performance of IPLS ( $\mathrm{r}=0.619)$ followed by the relationship between Information quality and Logistics Performance of IPLS ( $\mathrm{r}=0.550)$. The other constructs did have moderately strong relationship. 
European Journal of Logistics, Purchasing and Supply Chain Management

Vol.8 No.3, pp.17-38, August 2020

Published by ECRTD UK

ISSN 2054-0930 (Print), ISSN 2054-0949 (Online)

\subsection{Regression Analysis of IPLS Factors with User Satisfaction}

\section{Coefficients $^{\mathbf{a}}$}

\begin{tabular}{|c|c|c|c|c|c|c|}
\hline \multirow{2}{*}{\multicolumn{2}{|c|}{ Model }} & \multicolumn{2}{|c|}{$\begin{array}{c}\text { Unstandardized } \\
\text { Coefficients }\end{array}$} & \multirow{2}{*}{$\begin{array}{c}\begin{array}{c}\text { Standardized } \\
\text { Coefficients }\end{array} \\
\text { Beta }\end{array}$} & \multirow[t]{2}{*}{$\mathrm{t}$} & \multirow[t]{2}{*}{ Sig. } \\
\hline & & $\mathrm{B}$ & Std. Error & & & \\
\hline \multirow{5}{*}{1} & (Constant) & .883 & .262 & & 3.378 & .001 \\
\hline & System quality & -.042 & .072 & -.047 & -.581 & .563 \\
\hline & Information quality & .493 & .079 & .523 & 6.216 & .000 \\
\hline & Service Quality & .243 & .070 & .271 & 3.493 & .001 \\
\hline & Cultural factors & .134 & .048 & .175 & 2.786 & .006 \\
\hline
\end{tabular}

a. Dependent Variable: Overall user satisfaction

Table 9: Regression Analysis of IPLS attributes with user satisfaction

The regression table shows that all the independent variables have significant influence on the mediating variable except system quality which was not significantly correlated with user satisfaction at $\mathrm{R}^{2}$ of $54.7 \%$ as shown in table below:

\begin{tabular}{|l|r|r|r|r|}
\hline $\begin{array}{l}\text { Mode } \\
1\end{array}$ & \multicolumn{1}{|c|}{$\mathrm{R}$} & $\mathrm{R}$ Square & \multicolumn{1}{c|}{$\begin{array}{c}\text { Adjusted R } \\
\text { Square }\end{array}$} & Std. Error of the Estimate \\
\hline 1 & $.747^{\mathrm{a}}$ & .557 & .547 & .52802 \\
\hline
\end{tabular}

a. Predictors: (Constant), Overall cultural factors, Overall Info quality, Overall system quality

\section{Table 10: Adjusted R2}

Even though the system quality was not as good as it should be, overall information quality was acceptable as the system contributes something in performing organizational logistics tasks (Halawi et al., 2007; Dreheeb, Basir and Fabil, 2016 and Sirsat and Sirsat, 2016). Users lack confidence on the system quality due to human resource related matters such as turnover and low compensation as obtained from the interview. However, the system quality should be improved by proper training, maintaining the trained staff and motivating them to work for the better of the organization. 
European Journal of Logistics, Purchasing and Supply Chain Management

Vol.8 No.3, pp.17-38, August 2020

Published by ECRTD UK

ISSN 2054-0930 (Print), ISSN 2054-0949 (Online)

\subsection{Regression Analysis of User Satisfaction with Logistics Performance}

Regression between the mediating and the dependent variable were as follows:

\begin{tabular}{|c|c|c|c|c|c|c|}
\hline \multirow{2}{*}{\multicolumn{2}{|c|}{ Model }} & \multicolumn{2}{|c|}{$\begin{array}{l}\text { Unstandardized } \\
\text { Coefficients }\end{array}$} & \multirow{2}{*}{$\begin{array}{c}\begin{array}{c}\text { Standardized } \\
\text { Coefficients }\end{array} \\
\text { Beta }\end{array}$} & \multirow[t]{2}{*}{$\mathrm{t}$} & \multirow[t]{2}{*}{ Sig. } \\
\hline & & B & Std. Error & & & \\
\hline \multirow[b]{2}{*}{1} & (Constant) & 1.587 & .307 & & 5.169 & .000 \\
\hline & $\begin{array}{l}\text { Overall user } \\
\text { satisfaction }\end{array}$ & .634 & .072 & .619 & 8.805 & .000 \\
\hline
\end{tabular}

a. Dependent Variable: Overall logistics performance

Table 11: Regression Analysis of User Satisfaction with Logistics Performance

The mediating variable had significant and positive role on the dependent variable at $37.8 \%$ of adjusted $\mathrm{R}^{2}$. This is in line with the extant information systems literature and empirical findings as indicated for example in (Halawi et al., 2007; Dreheeb, Basir and Fabil, 2016 and Sirsat and Sirsat, 2016). The table below explains that $38.7 \%$ of logistics performance of HIV/AIDS commodities.

\section{Model Summary}

\begin{tabular}{|c|c|c|c|c|}
\hline $\begin{array}{c}\text { Mode } \\
1\end{array}$ & $\mathrm{R}$ & $\mathrm{R}$ Square & $\begin{array}{c}\text { Adjusted R } \\
\text { Square }\end{array}$ & $\begin{array}{c}\text { Std. Error of } \\
\text { the Estimate }\end{array}$ \\
\hline 1 & $.619^{\mathrm{a}}$ & .383 & .378 & .63409 \\
\hline
\end{tabular}

a. Predictors: (Constant), Overall user satisfaction

Table12: Adjusted R2 of the second Relationship

This implies that change in user satisfaction will influence Logistics performance of HIV/AIDS commodities. Satisfied users will use the system properly to perform their logistics tasks. The environment to motivate employees use the system properly should be in place to better use the IPLS for better logistics of HIV/AIDS commodities (Halawi et al., 2007; Dreheeb, Basir and Fabil, 2016 and Sirsat and Sirsat, 2016).

\section{CONCLUSIONS}

The data collected and analyzed indicated that the performance of IPLS has both strengths and weaknesses. For instance in terms of system quality, the system was not found to be error free and secured. But respondents stated that it was friendly to handle. The system quality was also compromised due to high turnover of trained staff and lack of skill upgrading training.

In terms of information quality, information accuracy of the system was questioned by the respondents. This is the same conclusion as what was stated for the system being error prone. The report formats are not also frequently updated and the employees complete the forms 
European Journal of Logistics, Purchasing and Supply Chain Management

Vol.8 No.3, pp.17-38, August 2020

Published by ECRTD UK

ISSN 2054-0930 (Print), ISSN 2054-0949 (Online)

carelessly. But information is easy to find from the system which is again in line with the above conclusion that the system is user friendly. In relation to cultural factors, power distance among team members within the organization doesn't affect system performance very much. However, individualism has more effect in the IPLS environment.

IPLS enhances job performance of users and increased their productivity which increases their satisfaction. Over all, the system was good in terms of enhancing user satisfaction which is the base for organization. IPLS resulted in big improvement in the accuracy of logistics by improving planning, decision making, productivity and overall logistics objectives. Improving IPLS performance will further improve Logistics performance of HIV/AIDS commodities.

The regression analysis indicated that all the independent variables (information quality, service quality, and cultural factors) have strong and positive effect on user satisfaction and thereby on Logistics performance of HIV/AIDS commodities except system quality. System quality did not have strong and positive effect on user satisfaction due to factors specific to the Ethiopian environment which were indicted in the interview such as turnover of trained staff, lack of skill upgrading trainings and other motivational factors such as compensation.

\section{IMPLICATIONS FOR PRACTICE AND FUTURE RESEARCH}

The findings of this study could be used by policy makers and practitioners in designing and implementing various types of information systems be it applicable in Human Resource Management, Logistics, Marketing, Accounting, Database Management, Enterprise Resource Planning Systems or any other type. Antecedents and consequences of Information Systems implementation could be observed by using the research model used in this study.

Future research may be conducted enriching this study in many ways such as incorporating other variables that affect IPLS from the extant literature, covering wider geographic area in Ethiopia as well as Eastern Africa and also incorporating private hospitals that operate side by side with public hospitals. Replicating the same study to observe the reliability of the outcomes of this study is another area of research for the future.

\section{REFERENCES}

Al-Jumeily, D. and Hussain, A.J. (2014) International Journal of Enhanced Research in Educational Development (IJERED), 2( 4), pp: (37-62), Available online at: www.erpublications.com

Berhane T. (2017) Assessment on implementation status of Integrated Pharmaceutical Logistic System for the Management of Health Commodities: the case of Public Health centers in Addis Ababa Ethiopia, Lead star College of Management and Leadership Facility of Business and Leadership Department of Business Administration (January, 2017)

Berhanemeskel et al. (2016) HIV/AIDS related commodities supply chain management in public health facilities of Addis Ababa, Ethiopia: a cross-sectional survey, Journal of Pharmaceutical Policy and Practice 9:11 
European Journal of Logistics, Purchasing and Supply Chain Management

Vol.8 No.3, pp.17-38, August 2020

Published by ECRTD UK

ISSN 2054-0930 (Print), ISSN 2054-0949 (Online)

Dreheeb, A.E., Basir, N. and Fabil. N. (2016) Impact of System Quality on Users' Satisfaction in Continuation of the Use of e-Learning System, International Journal of e-Education, e-Business, e-Management and e-Learning, 6(1)

FMOH .2010 Pharmaceuticals Fund and Supply Agency: integrated pharmaceutical logistics system (IPLS).

FMOH, (2011) Health Sector Development Plan-IV. Federal Ministry of Health, Addis Ababa, Ethiopia.

Ghasemi, A. \& Zahediasl, S. (2012) Normality Tests for Statistical Analysis: A Guide for NonStatisticians. Int J Endocrinol Metab, 10(2), PP486-9.

Halawi, L.A., McCarthy, R.V. and Aronson, J.E. (2007) An empirical investigation of knowledge management systems' success, Journal of Computer Information System, 48(2),121-135.

Hamilton, S. and Chervany, N.L. (1981) Evaluating information system effectiveness - Part II: Comparing evaluator viewpoints, MIS Quarterly, 5(4),79-86

Mudzteba, M. (2014) Assessment of Pharmaceutical Logistics System in Health Centers of Addis Ababa,

Mutugi, B. (2014) Factors Influencing the Effectiveness of Integrated Pharmacutical Logistics Systems in Public Health Sector: A case study of Kenya Medical Supplies Authority. The Requirement for Award of the Degree of Masters of Business Administration School of Business University of Nairobi. October 2014.

Nigussie, G., (2017) Assessment of Integrated Pharmaceutical Logistics System (IPLS) in Public Health Facilities at East Wollega Zone, Research Thesis submitted to the Department of Logistics and Supply Chain management, School of Commerce, Addis Ababa University in Partial Fulfillment of the Requirements for the Degree of Master of Art (MA)

PFSA, (2014) Integrated Pharmaceutical Logistics System: Changing the Supply Chain System of Ethiopia to Impact the Health Outcomes, Retrieved from http://www.pfsa.gov.et, on October 24, 2018.

PFSA, (2014) Standard operating procedure manual for the integrated pharmaceutical logistics system in health facilities of Ethiopia.

Romi, I.M. (2011) Organizational Culture Impact on Information Systems Success, Proceedings, $1^{\text {st }}$ Computer Science On-Line Conference in 2011, CSOC: 42-55

Sirsat, S. S. Sirsat M. S. (2012) A Validation of the Delone and Mclean Model on the Educational Information System of the Maharashtra State (India) International Journal of Education and Learning Systemshttp://iaras.org/iaras/journals/ijels

Taddesse, D. (2015) public sector pharmaceutical Integrated Pharmaceutical Logistics System: a cross-sectional assessment in selected antiretroviral service providing institutions, St. Mary's University School of Graduate Studies, MA thesis, retrieved from , repository.smuc.edu.et, on October 23,2018.

Tavakol,M. and Dennick, R. (2011) Making sense of Cronbach's Alpha, International Journal of Medical Education. Retrieved from Editorial ISSN: 2042-6372 DOI: 10.5116/ijme.4dfb.8dfd, on 25 March 2019. 
European Journal of Logistics, Purchasing and Supply Chain Management

Vol.8 No.3, pp.17-38, August 2020

Published by ECRTD UK

ISSN 2054-0930 (Print), ISSN 2054-0949 (Online)

Tilahun, A. (2014) Assessment of Integrated Pharmaceutical Logistic System for the Management HIV/AIDS and Tuberculosis Laboratory Diagnostic Commodities in Public Health Facilities in Addis Ababa, Ethiopia, Pharma Care Health Systems.

USAID PROJECT. (2011) Supply Chain Integration: Case Studies from Nicaragua, Ethiopia, and Tanzania. Arlington 13

USAID PROJECT. (2000) A Case study -assessing the effects of integration on supply chain performance and contraceptives security from Nicaraguan 